\title{
Nuevo Equipo de Dirección y Redacción
}

Ia Revista de Oncología, publicación oficial de la Federación de Sociedades Españolas de oncología (FESEO) y del Instituto Nacional de Cancerología de México, inicia con este número un nuevo período al producirse un recambio natural en algunos cargos de su equipo de dirección y redacción. El doctor Rafael Rosell termina su periplo como Editor Jefe tras un período enormemente fructífero para la revista, durante el cual ha sabido dar a la misma un aire nuevo y mucho más atractivo. Terminan asimismo sus obligaciones en el equipo de dirección y redacción Purificación García de Miguel y Enrique Murillo Capitán, mientras que se incorporan al mismo Soledad Gallego y Rosario Perona. Los Editores Ejecutivos, Juan Carlos Lacal, de Madrid, y Alejandro Mohar, de México D. F., así como los restantes miembros del Equipo de Dirección y Redacción continúan desempeñando sus actuales cargos. Tras la pertinente consulta con el Instituto Nacional de Cancerología de México, la Junta Directiva de la FESEO ha pensado en mí para la difícil $\begin{array}{llllll}t & a & r & e & a\end{array}$ de continuar la labor del doctor Rosell, reto que he acep-tado con entusiasmo, aunque también con preocupación por la dificultad que supone mantener el nivel de calidad en la Revista que el doctor Rosell ha marcado.

Quiero reseñar muy brevemente las líneas maes- tras que me gustaría que presidieran mi paso por el cargo de Editor Jefe de la Revista de Oncología, y que ya he discutido y consensuado con los Editores Ejecutivos, Juan Carlos Lacal y Alejandro Mohar. En primer lugar intentaremos que el camino de la Revista hacia el Index Medicus, verdadero termómetro de calidad de cualquier publicación médica, prosiga a la velocidad adecuada, estimulando la publicación de editoriales, originales y revisiones de la máxima calidad posible.

Además intentaremos abrir progresivamente la Revis-ta a los restantes países de habla hispana. Siempre nos han resultado poco comprensibles las escasas relaciones existentes entre los países hispanoparlantes en el terreno de la investigación oncológica y creemos que esta situación debería ser revisada en interés de todos.

Por último, intentaremos llevar a cabo un programa ex-perimental de control de calidad de datos en las publicaciones de ensayos clínicos. Realmente esta idea fue la que propició mi acercamiento a la Revista de Oncología. Hace pocos meses el doctor Rosell me solicitó un editorial sobre el fraude en Oncología y en él tuve la oportunidad de analizar la falta de control que las publicaciones médicas ejercen sobre la calidad de datos de los ensayos clínicos, así como exponer algunas posibles soluciones para este grave problema.

Quiero terminar agradeciendo desde aquí al doctor Javier Dorta su gentileza al sugerir mi nombre a la FESEO, a la Junta Directiva de la misma por la confianza depositada en mí y a Juan Carlos Lacal y Alejandro Mohar por su acogida en la Revista.

Miguel Martín Editor Jefe de la Revista de Oncología 